\title{
EPIDEMIOLOGICAL PROFILE, GASTROINTESTINAL TOXICITY, AND TREATMENT OF PELVIC CANCERS IN PATIENTS MANAGED WITH RADIOTHERAPY TO THE ABDOMINAL PELVIC AREA
}

\author{
Lucely Cetina-Pérez ${ }^{1}$, Alberto Serrano-Olvera ${ }^{4}$, Laura Flores-Cisneros ${ }^{1,5}$, Roberto Jiménez-Lima ${ }^{1,5}$, \\ Cristina Alvarado-Silva ${ }^{6}$, María del Consuelo Díaz-Romero ${ }^{1,2}$, Flavia Morales-Vásquez ${ }^{1,2}$, \\ David Eduardo Muñoz-González ${ }^{1,2}$, Aida Mota-García ${ }^{3}$, Oscar Armando Chávez-Fierro ${ }^{1}$, \\ Silvia Cristina Jaramillo-ManzUR ${ }^{1}$, Jaime de la Garza-Salazar ${ }^{1}$, Denisse Castro-Eguiluz ${ }^{7}$ \\ and Abelardo Meneses-García ${ }^{8 *}$ \\ ${ }^{1}$ Departments of Clinical Research and Medical Oncology, ${ }^{2} \mathrm{Gyneco-Oncology,}{ }^{3}$ Radio-Oncology, and ${ }^{8} \mathrm{General}$ \\ Direction, Instituto Nacional de Cancerología, Mexico City; ${ }^{4}$ Department of Medical Oncology, Hospital ABC, \\ Mexico City; ${ }^{5}$ Postgraduate Unit, Universidad Nacional Autónoma de México, Mexico City; ${ }^{6}$ Department of Medical \\ Oncology, Hospital Juárez de México, Mexico City; ${ }^{7}$ Consejo Nacional de Ciencia y Tecnología (CONACyT) - \\ Department of Clinical Research, Instituto Nacional de Cancerología, Mexico City, Mexico.
}

\begin{abstract}
Mexico has seen an increase in cancer prevalence in its entire population as well as particular age ranges, predominantly the older segment. The most frequently reported pelvic cancers in Mexico are cervical, endometrial, bladder, prostate, rectum, and anal canal. Approximately $80 \%$ of the population diagnosed with pelvic cancers present with locally advanced tumors and require concomitant chemoradiotherapy, sequential chemoradiotherapy, or radiotherapy alone. The toxicity of any of these treatment modalities may be manifested as intestinal injury, a significant problem that can compromise the response to treatment, the patient's nutritional state, quality of life, and survival. In this article, we will approach key aspects in nutrition as well as the epidemiological characteristics and toxicities in patients affected by these pelvic tumors. (REV INVES CLIN. 2018;70:112-6)
\end{abstract}

Key words: Epidemiology. Pelvic cancer. Radiotherapy. Chemotherapy. Gastrointestinal toxicity.

Corresponding author:

*Abelardo Meneses-García Instituto Nacional de Cancerología

Av. San Fernando, No. 22

Col. Sección XVI, Del. Tlalpan

C.P. 14080, Ciudad de México, México

E-mail: menesesabelardo@gmail.com

Received for publication: 03-03-2018

Accepted for publication: 03-05-2018

doi: $10.24875 / R I C .18002528$ 


\section{INTRODUCTION}

Cancer is an important public health problem throughout the world and particularly in Mexico. Some authors have reported a $15 \%$ global increase per year ${ }^{1}$. Mexico has also seen an increase in the incidence of cancer in its entire population in different age ranges but predominantly in individuals over 65 years of age $^{2}$. Pelvic tumors refer to those located within the anatomical area of the pelvis, which extends from the fourth lumbar vertebra to the anal triangle ${ }^{3}$. In our population, the most frequent pelvic cancers that have been treated with radiotherapy of the pelvic region are cervical, endometrial, bladder, prostate, rectum, and anal canal (Table 1 ).

Radiotherapy is one of the most important treatment modalities in cases of inoperable pelvic tumors. Treatment is administered with a curative intent in some cases - as in locally advanced stages - and as a palliative in more advanced cancers ${ }^{4}$.

In recent years, improved technology and the concerted efforts of physicists and physicians have transformed radiotherapy into a timely, efficient, and less toxic treatment modality. Furthermore, the introduction of advanced techniques such as intensity modulated radiation therapy, image-guided radiation therapy, and the CyberKnife has increased the precision of radiation treatments ${ }^{5-8}$. However, the toxicity resulting from radiotherapy alone, concomitant chemoradiotherapy, sequential chemoradiotherapy, and radiotherapy in its neoadjuvant, adjuvant, or palliative modalities, continues to be a problem compromising treatment response, the patient's nutritional state, quality of life, and survival in cases that develop pelvic radiation disease ${ }^{9-11}$.

Pelvic radiation disease may be defined as "transient or longer-term problems, ranging from mild to very severe, arising in non-cancerous tissues and resulting from radiotherapy treatment for a tumor of pelvic origin"12. There are two types of toxicity: "acute toxicity," defined as the toxicity manifested in "earlyreacting tissues" or rapid renewal tissues, such as the epithelial surfaces and bone marrow; injury is clinically manifested within days after initial radiation exposure and up to 90 days later. "Late toxicity" refers to that manifested in "late-reacting tissues" in which cellular turnover is much slower, such as connective tissue; injury may, therefore, become manifest months or even years after exposure and definitely after 90 days of finalizing treatment. Other toxic consequences include "indirect" effects, reactive phenomena that occur in response to radiation-induced injury in other cells or tissues, such as parenchymal cell depletion secondary to vascular damage; these effects also include "bystander" fallout and tissue reactions to cell lethality, including the effects of vasoactive, pro-coagulant, and inflammatory mediators, such as cytokines, growth factors, and chemokines ${ }^{12,13}$.

During the treatment period, which may range from 5 to 7 weeks or more, $80-90 \%$ of patients develop variable toxicity manifestations in the gastrointestinal tract and other pelvic organs ${ }^{14}$. Chronic radiation

Table 1. Incidence and mortality of pelvic cancers in Mexico

\begin{tabular}{|c|c|c|c|}
\hline \multirow[t]{2}{*}{ Cancer site } & \multicolumn{2}{|c|}{ Incidence } & Mortality \\
\hline & Number of cases*1 $(\%)$ & Standardized rate by age* & Number of cases* $(\%)$ \\
\hline Gynecological & & & 응 \\
\hline Uterine cervix & $13,960(16.9)$ & 23.3 & $4,769(11.9)$ \\
\hline Endometrial & $2,733(3.3)$ & 4.8 & $550(1.4)$ \\
\hline Urological & & & 4 \\
\hline Bladder & $3,245(2.2)$ & 2.9 & $1,166(1.5)$ \\
\hline Prostate & $14,016(21.4)$ & 27.3 & $6,367(8.1)$ \\
\hline Gastrointestinal & & & 은 \\
\hline Rectal ${ }^{31}$ & 1268 (ND) & 33.4 & $424(0.4)$ \\
\hline Anal canal ${ }^{32}$ & ND (0.18) & ND & ND (ND) \\
\hline Total & $42,605(37.7)$ & 66.1 & $17,546(28.9)$ \\
\hline
\end{tabular}

ND: not described; *Number of cases per 100,000 population. 
Table 2. Prevalence of toxicity symptoms in different cancer tumors

\begin{tabular}{|c|c|c|c|c|c|}
\hline Toxicity & Uterine cervix & Bladder & Anal/rectal & Prostate & Endometrial \\
\hline \multicolumn{6}{|l|}{ Hematologic (\%) } \\
\hline Leukopenia & $4-47$ & $2.9-8.6$ & $3-24$ & ND & 25.5 \\
\hline Neutropenia & ND & 2.9 & $<1-3$ & ND & ND \\
\hline Fatigue & $0-24$ & $5.7-31.4$ & $1.3-6.8$ & ND & 7.8 \\
\hline \multicolumn{6}{|l|}{ Gastrointestinal (\%) } \\
\hline Nausea/vomiting & $0-14$ & $2.9-31.4$ & $<1-5$ & ND & ND \\
\hline Rectal bleeding & ND & ND & ND & $<1-12$ & ND \\
\hline Diarrhea & $0-21$ & $2.9-31.4$ & $6.9-10$ & $<1-13$ & 11.8 \\
\hline Fecal incontinence & ND & ND & ND & ND & ND \\
\hline Abdominal pain & 1 & $2.9-20$ & $0.3-3.4$ & ND & ND \\
\hline Tenesmus & ND & ND & $1.4-5.5$ & ND & ND \\
\hline \multicolumn{6}{|l|}{ Genitourinary (\%) } \\
\hline Hematuria & ND & ND & ND & $<1-7.1$ & ND \\
\hline Dysuria & $0-17$ & $5.7-20$ & ND & $<1-26.8$ & ND \\
\hline Urinary incontinence & ND & ND & ND & $<1-10.7$ & ND \\
\hline Urinary frequency & ND & $5.7-20$ & ND & $<1-27.9$ & ND \\
\hline
\end{tabular}

$\%$ of patients presenting each symptom according to the type of tumor. ND: not described. Data were obtained from different sources: uterine cervix ${ }^{19,33}$ bladder $^{34}$, anal/rectal ${ }^{35,36}$, prostate $^{37,38}$, and endometrial ${ }^{39}$.

enteritis occurs in $0.5-16.9 \%$ of patients receiving abdominopelvic irradiation. Although symptoms may vary, these are remarkably similar to inflammatory bowel disease ${ }^{15,16}$ and are characterized by changes in bowel habits (94\%), occult fecal blood (80\%), increased frequency of bowel movements ( $74 \%)$, fecal urgency (39\%), fecal incontinence (37\%), and after treatment conclusion, and symptoms may persist in up to $50 \%$ of patients ${ }^{17}$. The prevalence of these symptoms may vary according to the area irradiated and the type of treatment applied (Table 2).

There are different clinical scales to measure oncologic toxicities. Among the most important are toxicity criteria CTCAE v. 4-5, RTOG, EORTC, and Lentsoma; these have been validated and are used as international criteria ${ }^{18-20}$.

Other ways to evaluate toxicity include molecular techniques that measure the expression of inflammatory mediators in peripheral blood, such as citrulline, C-reactive protein, eosinophil cationic protein, inflammatory cytokines, and the determination of gene expression ${ }^{21-25}$. Other authors have reported that the neutrophil-derived proteins, calprotectin, and lactoferrin are important molecules directly related to gastrointestinal toxicity and inflammation ${ }^{25}$. Further, due to the inflammatory response generated during the acute phase, Th1 and Th2 immune responses may also play a significant role in radiotherapy-induced inflammation ${ }^{26}$.

Several factors have been correlated with the risk of developing late post-irradiation complications in gynecologic malignancies ${ }^{27,28}$. These factors could perhaps help predict and prevent late normal tissue injury. In their paper, Heemsbergen et aP. studied whether there is a direct relationship between acute and late gastrointestinal toxicity, concluding that acute gastrointestinal toxicity is an independent significant predictor of late gastrointestinal toxicity ${ }^{28}$. There was no correlation between acute and late urinary toxicity ${ }^{27,28}$.

Other factors that may influence late bowel toxicity are the patient's age and gender, tumor location, tumor size, tumor volume, and the number of daily bowel movements. In addition, some comorbidities such as inflammatory bowel disease, immune dysregulation, abnormal microbial flora, environmental factors, and genetic susceptibility could also influence the development of gastrointestinal toxicity ${ }^{16,29}$.

Radiotherapy causes damage to the gastrointestinal mucosa and affects secretory and absorptive functions that, in turn, may interfere with normal 
gastrointestinal physiology as well as nutrient absorption and digestion. It is manifested 2 weeks after radiotherapy is initiated and is dependent on the fraction dosage and radiation volume. It leads to changes in the intestinal flora and increases in mucosal cell permeability and intestinal motility as well as to the generation of free oxygen radicals and subsequent vascular insufficiency, ischemia, fibrosis, intestinal obstruction, chronic proctitis, and the development of fistulae. Clinically, these signs are translated as a malabsorption syndrome. Histopathologic changes are also observed, including thickening of the serosa, mucosal ulcerations, epithelial atypia, vascular sclerosis, intestinal wall fibrosis, lymph congestion, and ileitis cystica profunda ${ }^{30}$.

Some pharmacological interventions have attempted to prevent or at least diminish the damage described; they have achieved a slight reduction in the severity of the symptoms of gastrointestinal toxicities, but to date, conclusive findings are limited.

Nutritional intervention has been deemed necessary to maintain the nutritional status of the patient during treatment, to avoid malnutrition, to decrease the severity of treatment, and finally, to improve response to treatment. In this consensus, we pretend to lay the groundwork for dietary intervention and describe the available nutritional tools used to assess the patient's nutritional status and possible nutritional interventions that may modify the patient's course.

\section{REFERENCES}

1. Ferlay J, Soerjomataram I, Dikshit R, et al. Cancer incidence and mortality worldwide: sources, methods and major patterns in GLOBOCAN 2012. Int J Cancer. 2015;136:E359-86.

2. Ríos PR, Rivera AG, Cervantes FS, Martínez PM. Tendencia de la mortalidad por cáncer en México: 1990-2012. Evid Méd Invest Salud. 2015;8:5-15.

3. Netter FH. Atlas of Human Anatomy. Professional Edition. 5th ed. Philadelphia: Saunders; 2010.

4. National Comprehensive Cancer Network. NCCN Clinical Practice Guidelines in Oncology: cervical Cancer.V 1.2016. J Natl Compr Canc Netw. 2016;64:???

5. Gandhi AK, Sharma DN, Rath GK, et al. Early clinical outcomes and toxicity of intensity modulated versus conventional pelvic radiation therapy for locally advanced cervix carcinoma: a prospective randomized study. Int J Radiat Oncol Biol Phys. 2013; 87:542-8.

6. Viswanathan AN, Yorke ED, Marks LB, Eifel PJ, Shipley WU. Radiation dose-volume effects of the urinary bladder. Int J Radiat Oncol Biol Phys. 2010;76:S116-22.

7. Teo MT, Sebag-Montefiore D, Donnellan CF. Prevention and management of radiation-induced late gastrointestinal toxicity. Clin Oncol (R Coll Radiol). 2015;27:656-67.
8. Susko M, Craciunescu O, Meltsner S, et al. Vaginal dose is associated with toxicity in image guided tandem ring or ovoidbased brachytherapy. Int J Radiat Oncol Biol Phys. 2016; 94:1099-105.

9. Gondi V, Bentzen SM, Sklenar KL, et al. Severe late toxicities following concomitant chemoradiotherapy compared to radiotherapy alone in cervical cancer: an inter-era analysis. Int J Radiat Oncol Biol Phys. 2012;84:973-82.

10. van de Wetering FT, Verleye L, Andreyev HJ, et al. Non-surgical interventions for late rectal problems (proctopathy) of radiotherapy in people who have received radiotherapy to the pelvis. Cochrane Database Syst Rev. 2016;4:CD003455.

11. Nout RA, Putter H, Jürgenliemk-Schulz IM, et al. Five-year quality of life of endometrial cancer patients treated in the randomised post operative radiation therapy in endometrial cancer (PORTEC-2) trial and comparison with norm data. Eur J Cancer. 2012;48:1638-48.

12. Andreyev HJ, Wotherspoon A, Denham JW, Hauer-Jensen M Defining pelvic-radiation disease for the survivorship era. Lancet Oncol. 2010;11:310-2.

13. Denham JW, Hauer-Jensen M, Peters LJ. Is it time for a new formalism to categorize normal tissue radiation injury? Int J Radiat Oncol Biol Phys. 2001;50:1105-6.

14. Khalid U, McGough C, Hackett C, et al. A modified inflammatory bowel disease questionnaire and the vaizey incontinence questionnaire are more sensitive measures of acute gastrointestinal toxicity during pelvic radiotherapy than RTOG grading. Int J Radiat Oncol Biol Phys. 2006;64:1432-41.

15. MacNaughton WK. Review article: new insights into the pathogenesis of radiation-induced intestinal dysfunction. Aliment Pharmacol Ther. 2000;14:523-8.

16. Kaser A, Zeissig S, Blumberg RS. Inflammatory bowel disease. Annu Rev Immunol. 2010;28:573-621.

17. Wedlake L, Slack N, Andreyev HJ, Whelan K. Fiber in the treatment and maintenance of inflammatory bowel disease: a systematic review of randomized controlled trials. Inflamm Bowe Dis. 2014;20:576-86.

18. National Institute of Cancer. Common Terminology Criteria for Adverse Events ( CTCAE ), Version 4.0, DCTD, CTI, NIH, DHHS.; 2009

19. Maduro JH, Pras E, Willemse PH, de Vries EG. Acute and longterm toxicity following radiotherapy alone or in combination with chemotherapy for locally advanced cervical cancer. Cancer Treat Rev. 2003;29:471-88.

20. Cox JD, Stetz J, Pajak TF. Toxicity criteria of the radiation therapy oncology group (RTOG) and the european organization for research and treatment of cancer (EORTC) Int J Radiat Oncol Biol Phys. 1995;31:1341-6.

21. Jones JW, Tudor G, Li F, et al. Citrulline as a biomarker in the murine total-body irradiation model: correlation of circulating and tissue citrulline to small intestine epithelial histopathology. Health Phys. 2015;109:452-65.

22. Lutgens LC, Deutz NE, Gueulette J, et al. Citrulline: a physiologic marker enabling quantitation and monitoring of epithelial radiation-induced small bowel damage. Int J Radiat Oncol Biol Phys. 2003;57:1067-74

23. Papadia C, Sherwood RA, Kalantzis C, et al. Plasma citrulline concentration: a reliable marker of small bowel absorptive capacity independent of intestinal inflammation. Am J Gastroenterol. 2007:102:1474-82.

24. Lutgens $L$, Lambin P. Biomarkers for radiation-induced small bowel epithelial damage: an emerging role for plasma citrulline. World J Gastroenterol. 2007;13:3033-42.

25. Limburg PJ, Ahlquist DA, Sandborn WJ, et al. Fecal calprotectin levels predict colorectal inflammation among patients with chronic diarrhea referred for colonoscopy. Am J Gastroenterol. 2000;95:2831-7.

26. Indaram AV, Visvalingam V, Locke M, Bank S. Mucosal cytokine production in radiation-induced proctosigmoiditis compared with inflammatory bowel disease. Am J Gastroenterol. 2000; 95:1221-5.

27. Jereczek-Fossa BA, Jassem J, Badzio A. Relationship between acute and late normal tissue injury after postoperative radiotherapy in endometrial cancer. Int J Radiat Oncol Biol Phys. 2002;52:476-82

28. Heemsbergen WD, Peeters ST, Koper PC, Hoogeman MS, Lebesque JV. Acute and late gastrointestinal toxicity after radiotherapy in prostate cancer patients: consequential late damage. Int J Radiat Oncol Biol Phys. 2006;66:3-10.

29. Xu B, Guo Y, Chen Y, et al. Is the irradiated small bowel volume still a predictor for acute lower gastrointestinal toxicity during 
preoperative concurrent chemo-radiotherapy for rectal cancer when using intensity-modulated radiation therapy? Radiat Oncol. 2015;10:257.

30. Demirer S, Aydintug S, Aslim B, et al. Effects of probiotics on radiation-induced intestinal injury in rats. Nutrition. 2006;22: 179-86.

31. Tirado L, Mohar A. Epidemiología del Cáncer de Colon y Recto. Vol. 7. ???: ???; 2008

32. Ruiz Molina JM, Aceytuno RG, Rincón DG, et al. Cáncer de canal anal. Rev Gastroenterol Mex 1997;62:184-8.

33. Cetina L, Rivera L, Hinojosa J, et al. Routine management of locally advanced cervical cancer with concurrent radiation and cisplatin. Five-year results. BMC Womens Health. 2006;6:3.

34. De Santis M, Bachner M, Cerveny M, et al. Combined chemoradiotherapy with gemcitabine in patients with locally advanced inoperable transitional cell carcinoma of the urinary bladder and/or in patients ineligible for surgery: a phase I trial. Ann Oncol. 2014;25:1789-94.

35. Allegra CJ, Yothers G, O'Connell MJ, et al. Neoadjuvant 5-FU or capecitabine plus radiation with or without oxaliplatin in rectal cancer patients: a phase III randomized clinical trial J Natl Cancer Inst. 2015;107:1-8.

36. James RD, Glynne-Jones R, Meadows HM, et al. Mitomycin or cisplatin chemoradiation with or without maintenance chemotherapy for treatment of squamous-cell carcinoma of the anus (ACT II): a randomised, phase 3 , open-label, $2 \times 2$ factorial trial. Lancet Oncol. 2013;14:516-524.

37. Olarte $A$, Cambeiro $M$, Moreno-Jiménez $M$, et al. Dose escalation with external beam radiation therapy and high-dose-rate brachytherapy combined with long-term androgen deprivation therapy in high and very high risk prostate cancer: comparison of two consecutive high-dose-rate schemes. Brachytherapy. 2016;15:127-35

38. Warde $\mathrm{P}$, Mason $\mathrm{M}$, Ding $\mathrm{K}$, et al. Combined androgen deprivation therapy and radiation therapy for locally advanced prostate cancer: a randomised, phase 3 trial. Lancet. 2011;378: 2104-11.

39. Wilkinson-Ryan I, Binder PS, Pourabolghasem S, et al. Concomitant chemotherapy and radiation for the treatment of advancedstage endometrial cancer. Gynecol Oncol. 2014;134:24-8. 